\title{
Erectile Dysfunction Clinic: Exploring Drivers and Barriers to Seeking Help
}

\section{Dr SJ Megarity, Dr E McCarty, Dr L Bell, Dr W Dinsmore \\ Royal Victoria Hospital, Belfast}

\section{Background}

Erectile dysfunction (ED) may affect up to half of men in their lifetime. Barriers can prevent discussion of symptoms with their GP and on occasions they will present at GUM clinics. Understanding these barriers can be useful in assessing their experiences and expectations of treatment.

\section{Methods}

An anonymous self-administered questionnaire was issued to new patients attending the ED clinic. Sexual Health Inventory for Men (SHIM) score used to classify ED severity.

\section{Results}

75 patients with median age of 52 years (range 19-78 years) participated.

93\% had significant co-morbidities or vascular risk factors.

\begin{tabular}{|c|c|}
\hline SHIM score & $\begin{array}{ll}-47 \% \text { severe ED } & \bullet 16 \% \text { moderate ED } \\
\bullet 26 \% \text { mild-moderate ED } & \bullet 11 \% \text { mild ED }\end{array}$ \\
\hline Duration of ED & - Duration of ED was greater than 5 years in $53 \%$ of patients \\
\hline Quality of Life & $\begin{array}{l}\text { - } 49 \% \text { reported significant impact on quality of life } \\
\text { - } 43 \% \text { report some impact on quality of life } \\
\text { - } 40 \% \text { had underlying depression and/or anxiety }\end{array}$ \\
\hline Importance of Treatment & $\begin{array}{l}\text { - Important or very important in } 96 \% \text { of patients } \\
\text { - Relationship difficulties prompted } 65 \% \text { patients to seek help }\end{array}$ \\
\hline Barriers & $\begin{array}{l}\text { - Embarrassment prevented } 47 \% \text { of patients seeking help } \\
\text { - Lack of treatment awareness prevented } 29 \% \text { of patients seeking help }\end{array}$ \\
\hline Discussion of ED & $\begin{array}{l}-85 \% \text { of patients prompted the discussion with their GP } \\
\text { - } 73 \% \text { discussed ED with their partner } \\
\text { - } 16 \% \text { discussed ED with a friend or relative }\end{array}$ \\
\hline Knowledge of ED & $\begin{array}{l}\text { - } 88 \% \text { reported limited knowledge of ED treatments prior to attendance } \\
\text { - } 77 \% \text { suggested patient information leaflets would be useful prior to clinic } \\
\text { attendance }\end{array}$ \\
\hline Prior treatment & $\begin{array}{l}\text { - } 65 \% \text { of patients had received treatment prior to attendance at ED clinic } \\
\text { - } 9 \% \text { of this treatment was self-sourced }\end{array}$ \\
\hline
\end{tabular}

\section{Conclusions}

Patients presenting with ED often delay seeking advice. Medical comorbidities, relationship difficulties and embarrassment are significant issues affecting patients which should be taken into consideration during consultations. Providing patients with a patient information leaflet prior to first attendance may be useful. 